\title{
Gastroskopik incelemede mide polip sıklığı ve bu poliplerin yerleşim, boyut ve histopatolojik özellikleri
}

Prevalence of gastric polyps during upper gastrointestinal system endoscopy and their location, size, and histopathologic features

Mesut SEZIKLI ${ }^{1}$, Züleyha AKKAN ÇETINKAYA ${ }^{1}$, Göktuğ ŞIRINN¹ ${ }^{1}$ Fatih GÜZELBULUT ${ }^{2}$, Galip Egemen ATAR ${ }^{3}$, Didem EROĞLU³ , Emre DÖNMEZ

Kocaeli Derince Eğitim ve Araş̧tırma Hastanesi ${ }^{1}$ Gastroenteroloji Kliniği, ${ }^{3}$ Iç Hastalıklan Kliniği, Kocaeli

Bakırköy Sadi Konuk Eğitim ve Araștırma Hastanesi ²Gastroenteroloji Kliniğ̈i, Istanbul

Giriș ve Amaç: Üst gastrointestinal sistem endoskopisi esnasında saptanan mide poliplerinin siklık, yerleşim, boyut ve histopatolojik özelliklerinin araștırılması. Gereç ve Yöntem: Ocak 2012-Aralık 2013 tarihleri arasında Kocaeli Derince Eğitim ve Araştırma Hastanesi Gastroenteroloji Endoskopi Ünitesinnde yapılan 6607 üst gastrointestinal sistem endoskopisi esnasında mide polip saptanan 123 hastanın verilerini retrospektif olarak inceledik. Poliplerin yerleşim yeri, boyutu, histopatolojik özelliği, Helicobacter pylor pozitifliği ve proton pompa inhibitörü kullanımı kaydedildi. Bulgular: Poliplerin 14 tanesi $(\% 11,4)$ fundusta, 20 tanesi $(\% 16,3)$ korpusta ve 50 tanesi $(\% 40,7)$ antrumda idi. 81 tanesi $(\% 65,9)$ hiperplastik polip, 1 tanesi $(\% 0,89)$ fundik gland polip ve 13 tanesi $(\% 10,6)$ adenomatöz polip idi. Hiperplastik poliplerde Helicobacter pylori pozitifliği, diğer polipler göre daha sıkt (\%42'ye \% 14,6) ( $p=0,002)$. Sonuç: Mide polipleri üst gastrointestinal sistem endoskopisi esnasında sıklıkla karşımıza çıkabilmektedir. En sık hiperplastik polip izlense de malignleşme potansiyeli olan poliplerle de karşılaşabiliriz. Bu çalışmada fundik gland poliplerin oranı literatüre göre düşük iken, adenomatöz polip oranı benzerdi.

Anahtar kelimeler: Gastroskopik inceleme, mide polibi

\section{GİRISs}

Mide polipleri sıklıkla değişik nedenlerle yapılan gastroskopik işlemler sırasında rastlantısal olarak saptanır. Bazen de kanama, pilor çıkış obstrüksiyonu, demir eksikliği anemisi, karın ağrısına neden olabilmektedirler $(1,2)$.

Mide polipleri genel popülasyonda \%0,8-2,4 arasinda görülür $(3,4)$. Çoğunluğunu hiperplastik ve fundik gland polipleri küçük bir kısmını ise adenomatöz polipler oluşturur $(4,5)$. Bununla beraber Helikobakter pilori’nin $(\mathrm{Hp})$ sik görüldüğü bölgelerde fundik polipler, adenomatöz poliplere göre belirgin olarak daha az görülür $(6,7)$. Histolojik olarak, epitel veya submukozadan köken alıp lümene doğru büyürler (8).

Çoğunlukla benign karakterde olmakla birlikte nadiren malignleşme potansiyelleri vardır. Mide polipoid lezyonları Dünya Sağlık Örgütü (WHO) sınıflandırılması Şekil l'de gösterilmiştir (9).

$\mathrm{Bu}$ çalışmanın amacı gastroskopik inceleme sırasında polip rastlama sıklığı ve bu poliplerin yerleşim, boyut ve histopatolojik özelliklerinin araştırılmasıdır.

Sezikli M, Çetinkaya Akkan Z, Şirin G, et al. Prevalence of gastric polyps during upper gastrointestinal system endoscopy and their location, size, and histopathologic features. Endoscopy Gastrointestinal 2014; 22: 38-40.
Background and Aims: We aimed to evaluate the location, size and histopathologic features of gastric polyps detected during upper gastrointestinal system endoscopy. Materials and Methods: We retrospectively evaluated the data of 123 of 6607 patients who were diagnosed to have gastric polyps during upper gastrointestinal system endoscopy in Kocaeli Derince Education and Research Hospital, Gastroenterology Endoscopy Unit, between January 2012 and December 2013. The location, size, histopathologic features, Helicobacter pylori positivity, and use of proton pump inhibitors were recorded. Results: 14 (11.4\%) of the polyps were located in the fundus, $20(16.3 \%)$ in the corpus, and $50(40.7 \%)$ in the antrum. Histopathologically, 81 (65.9\%) were hyperplastic, 1 (0.89\%) was a fundic gland polyp, and $13(10.6 \%)$ were adenomatous. Helicobacter pylori positivity was more common in hyperplastic polyps than in the other polyps (42\% vs 14.6\%) ( $p=0.002)$. Conclusions: Gastric polyps are detected commonly during upper gastrointestinal system endoscopy. Although most are hyperplastic polyps, premalignant polyps may also be seen. In the present study, the ratio of fundic gland polyps was lower than in the literature, whereas the ratio of adenomatous polyps was similar.

Key words: Gastroscopic examination, gastric polyps

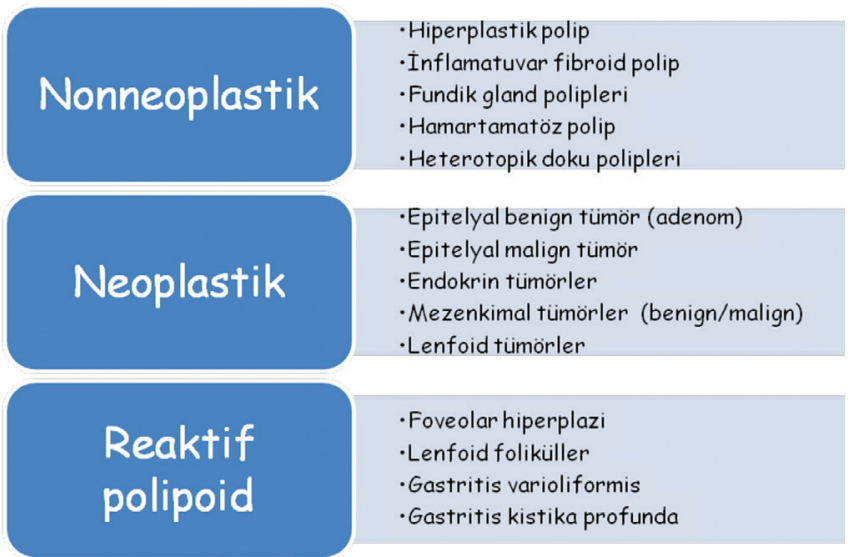

Şekil 1. Mide polipoid lezyonları WHO sınıflaması

\section{GEREC ve YÖNTEM}

Ocak 2012-Aralık 2013 tarihleri arasında Kocaeli Derince Eğitim ve Araştırma Hastanesi Gastroenteroloji endoskopi ünitesinde yapılan toplam 6607 üst gastrointestinal endosko- 


\begin{tabular}{lcc} 
Tablo 1. Poliplerin yerlessim yerleri & & \\
Polip lokalizasyonu & N & $\%$ \\
\hline Antrum & 50 & 40,7 \\
\hline Korpus & 20 & 16,3 \\
\hline Fundus & 14 & 11,4 \\
\hline Özofagus & 9 & 7,3 \\
\hline Kardia & 6 & 4,9 \\
Duodenum & 5 & 4,1 \\
\hline Diğer & 19 & 15,4 \\
\hline
\end{tabular}

\begin{tabular}{lcc} 
Tablo 2. Poliplerin histopatolojik sonuçları & \\
\hline Histopatoloji & $\mathrm{N}$ & $\%$ \\
Hiperplastik polip & 81 & 65,9 \\
\hline Adenomatöz polip & 13 & 10,6 \\
\hline Inflamatuar polip & 9 & 7,3 \\
\hline Intestinal metaplazi & 15 & 12,2 \\
\hline Fundik gland polibi & 1 & 0,8 \\
\hline Hamartamatöz kistik polip & 1 & 0,8 \\
\hline Adenokarsinom & 2 & 1,6 \\
\hline Nöroendokrin tümör & 1 & 0,8 \\
\hline
\end{tabular}

Tablo 3. Hiperplastik polip türüne göre hastaların özellikleri

\begin{tabular}{|lccc} 
& Hiperplastik polip & Diğer hastalar & p \\
\hline Cinsiyet (K/E) & $50 / 31$ & $25 / 17$ & 0,81 \\
\hline Yaş (ort \pm SD) & $58,83 \pm 13,70$ & $58,28 \pm 12,50$ & 0,82 \\
\hline En sık başvuru şikayeti (\%) & $\% 72,8$ dispepsi & $\% 75,6$ dispepsi & 0,12 \\
\hline Uzun PPI kullanımı (\%) & 28,4 & 24,4 & 0,63 \\
\hline Hp varlığı (\%) & 42 & 14,6 & 0,002 \\
\hline Polip boyutu (ort \pm SD, mm) & $6,99 \pm 3,99$ & $7,26 \pm 3,71$ & 0,71
\end{tabular}

\begin{tabular}{|c|c|c|c|}
\hline & Adenomatöz polip & Diğer hastalar & $\mathrm{p}$ \\
\hline Cinsiyet (K/E) & $9 / 4$ & $66 / 44$ & 0,51 \\
\hline Yaş (orttSD) & $63,84 \pm 11,39$ & $58,03 \pm 13,37$ & 0,13 \\
\hline En sık başvuru şikayeti (\%) & $\% 76,9$ dispepsi & $\% 73,4$ dispepsi & 0,89 \\
\hline Uzun PPI kullanımı (\%) & 23,1 & 27,5 & 0,73 \\
\hline$H p$ varlığı $(\%)$ & 30,8 & 33 & 0,87 \\
\hline Polip boyutu (ort $\pm S D, \mathrm{~mm}$ ) & $7,92 \pm 2,10$ & $6,98 \pm 4,04$ & 0,41 \\
\hline
\end{tabular}

Tablo 5. İnflamatuvar polip türüne göre hastaların özellikleri

\begin{tabular}{lccc} 
& Inflamatuvar polip & Diğer hastalar & $\mathrm{p}$ \\
\hline Cinsiyet (K/E) & $7 / 2$ & $68 / 46$ & 0,28 \\
\hline Yaş (ort \pm SD) & $52,66 \pm 10,86$ & $59,12 \pm 13,35$ & 0,16 \\
\hline En sık başvuru şikayeti (\%) & $\% 75$ dispepsi & $\% 73,7$ dispepsi & 0,94 \\
\hline Uzun PPI kullanımı (\%) & 25 & 27,2 & 0,89 \\
\hline Hp varlığı (\%) & 0 & 35,1 & 0,041 \\
Polip boyutu (ort \pm SD, mm) & $5,78 \pm 2,94$ & $7,18 \pm 3,94$ & 0,29
\end{tabular}

pi işlemi sırasında saptanan 123 gastrik polip hastasının verileri retrospektif olarak incelendi. Bu 123 vakadan çıkarılan poliplerin yerleşim yeri, boyutu, histopatolojik özelliği, Hp pozitifliği ve proton pompa inhibitörü (PPI) kullanımı kaydedildi. Isşlemler lokal anestezi (\%10 lidokain) ile yapılmıştır. Tüm polipler biyopsi forsepsi ( $<5 \mathrm{~mm}$ ) ile çıkarıldı veya koter kullanılarak endoskopik polipektomi yapıldı.

\section{BULGULAR}

Çalışmaya 75'i (\%61) kadın ve 48'i (\%39) erkek olan toplam 123 hasta alındı. Bu süre içerisinde yapılan toplam 6607 gastroskopi işleminde toplam 123 hastada polip saptandı (\%1.86). Polip hastalarının yaşları 22 ile 85 yıl arasında değişmekteydi ve hastaların yaş ortalaması 58,65 $\pm 13,25$ yıl idi. Poliplerin lokalizasyonu 50 olguda $(\% 40,7)$ antrum, 14 olguda $(\% 11,4)$ fundus, 20 olguda $(\% 16,3)$ korpus, 9 olguda $(\% 7,3)$ özofagus, 5 olguda $(\% 4,1)$ duodenum, 6 olguda $(\% 4,9)$ kardia ve 19 olguda $(\% 15,4)$ hiatal herni cebi, stoma kenarı ve anastamoz hattı gibi diğer bölgelerdeydi (Tablo 1).

Poliplerden alınan biyopsi materyallerinin histopatolojisi Tablo 2'de gösterildi. Hiperplastik polip, adenomatöz polip ve inflamatuvar polip en sik saptanan poliplerdi.

Başvuru şikayetlerine bakıldığında olguların \% 76,2'sinde (n:90) dispepsi, \%22'sinde (n:27) anemi, \%3,2'sinde (n:4) kanama ve \%1,6'sında (n:2) siroz ile ilişkili yakınmalar vardı. Genel olarak hastaları \%32,5'inde (n:40) Hp ve \%27,6'sında (n:34) 1 yıldan uzun süreli PPI kullanım öyküsü vardı.

En sık saptan polip türlerine göre hastaların özellikleri Tablo 3,4 ve 5 'te gösterildi.

\section{TARTIŞMA}

Mide polipleri genel popülasyonda \%0,8-2,4 arasında görülür $(3,4)$. Bizim polip sıklığımız \%1,86 idi ve literatürle uyumlu idi.

Hiperplastik polipler mide poliplerinin \%75-90'ını oluştururlar. Non-neoplastik nitelikteki bu polipler, yaşlılarda sıktır, 6 . ve 7 . dekadlarda pik yaparlar. Cinsiyete göre görülme sıklıkları değişmez $(6,7,10)$. Hiperplastik polipler kronik inflamatuvar uyarıya bağlı olarak epitelin aşırı rejenerasyonu sonucu oluşur (11). Genellikle benign olup nadiren malignleşme potansiyelleri vardır. Malignleşme riski, polip histopatolojisinin intestinal metaplazi veya displazi odağı içerip içermemesi ile alakalıdır (12). Fokal displazik odaklar \%1-20 arası hastada izlenir $(13,14)$.

Biz literatürle uyumlu olarak en sık hiperplastik polip saptadık $(\% 65,9)$. Ayrıca hiperplastik polipler, Hp enfeksiyonu ve atrofik gastrit ile ilişkilidir. Hp enfeksiyonunun sık olduğu coğrafik bölgelerde hiperplastik ve adenomatöz poliplerin, fundik gland poliplerinden daha sık görüldüğü bilinmektedir $(6,7,15)$. Bizim hastalarımızda $H p$ pozitifliği diğer poliplere göre istatiksel olarak anlamlı olarak daha yüksek oranda idi $(\mathrm{p}<0,05)$.

Fundik gland polipleri yerleşim yeri olarak ve endoskopik görünüm olarak diğer poliplerden farklılık gösterir. PPI yoğun 
kullananlarda, Zollinger-Ellison sendromu gibi hipergastrinemi ile seyreden durumlarda sik görülmektedir $(6,16,17)$.

Çoğunlukla benign kabul edilmekle birlikte familial adenamatoz polipozis (FAP) sendromlu hastalara eşlik edebileceği akılda tutulmalıdır. 20'den fazla, antrumda yerleşimli ve 40 yaş altı hastada saptanan fundik gland poliplerinde FAP taraması yapılmalıdır. Yapılan bir çalışmada 5 yıllık PPI kullanıminda fundik gland polip riskinin 3.8 kat arttı̆̆ gösterilmiştir $(10,18)$. Bu polipler $1 \mathrm{~cm}$ 'den büyükse malignleşme riski ortalama \%1 olarak kabul edilir (11). Ülsere veya antrumda lokalize iseler de malignleşme riski artmıştır. Bizim serimizde fundik gland polip oranı literatürün altındadır. Bunun nedeni; farkındalık azlığına, Helikobakter pilori enfeksiyonunun sık olduğu coğrafik bölgelerde hiperplastik ve adenomatöz poliplerin, fundik gland poliplerinden daha sık görüldügü bilgisine, uzun süreli PPI kullanan hasta sayısının az olmasına bağlanabilir.

Adenomatöz polipler ise mide poliplerinin \%6-10'unu oluşturur $(17,19)$. Adenomatöz polipler diğer iki polip çeşidinin tersine malignleşme riski içerirler. Seri endoskopi takiplerinde 4 yll içerisinde \%11 displazi veya karsinoma in-situya ilerledikleri gösterilmiştir (20). Bizim serimizde de literatürle uyumlu olarak \%10 oranında adenomatöz polip, bir adet de adenokarsinom saptanmıştır. Genellikle kronik gastrit ve intestinal metaplazi gösteren mukozada gelişirler. Sıklıkla tek ve büyüktürler, sesil ya da saphı olabilirler. Histopatolojik özelliklerine göre tübüler, villöz, tübülovillöz olarak adlandırlırlar. Adenomatöz poliplerin yaklaşık \%90'nını tübüler adenom, \%510’unu tübülo- villöz ve \%1-2'sini de villöz tiptekiler oluşturur $(6,7)$. Tübüler adenomlarda malignite gelişme riski daha azken, villöz ve tübülovillöz adenomlarda bu risk \%33 olarak bildirilmektedir (21).

Dokuz hastada raporlanan inflamatuvar polip, rutin polip s1niflamasında olmayan bir tanıdır. İflamasyona sekonder mukozal cevaba bağlı olarak gelişen polipoid oluşumlar endoskopist tarafından polip olarak değerlendirilebilir. Ayrıca serilerde $\% 0.1$ oranında izlenen inflamatuvar fibroid, polip mukoza ve submukozadan kaynaklanan mezenkimal bir tümördür. Immunohistokimyasal çalışmalar dentritik hücrelerden köken aldığını düşündürmektedir (22). Diğer nadir görülen poliplere ise makroskopik görünümden ziyade histopatolojik olarak tanı konabilmektedir.

Sonuç olarak; bizim hastalarımızda da literatürle uyumlu olarak en sık hiperplastik polipler izlenmiştir. Helikobakter pilori sıklığı anlamlı olarak hiperplastik poliplerle ilişkili bulunmuştur. Fundik gland poliplerini daha az oranda saptamamızı ise toplumda Helikobakter pilori pozitifliğimizin yüksekliğine bağladık.

\section{KAYNAKLAR}

1. Al-Haddad M, Ward EM, Bouras EP, Raimondo M. Hyperplastic polyps of the gastric antrum in patients with gastrointestinal blood loss. Dig Dis Sci 2007;52:105-9.

2. Kumar A, Quick CR, Carr-Locke DL. Prolapsing gastric polyp, an unusual cause of gastric outlet obstruction: a review of the pathology and management of gastric polyps. Endoscopy 1996;28:452-5.

3. Voutilainen M, Mäntynen T, Kunnamo I, et al. Impact of clinical symptoms and referral volume on endoscopy for detecting. Scand J Gastroenterol 2003;38:109-13.

4. Burt RW. Gastric fundic gland polyps. Gastroenterology 2003;125:14629.

5. Borch K, Skarsgård J, Franzén L, et al. Benign gastric polyps: morphological and functional origin. Borch K, Skarsgård J, Franzén L, Mårdh S Rehfeld JF. Dig Dis Sci 2003;48:1292-7.

6. Archimandritis A, Spiliadis C, Tzivras M, et al. Gastric epithelial polyps: a retrospective endoscopic study of 12974 symptomatic patients. Ital J Gastroenterol 1996;28:387-90.

7. Morais DJ, Yamanaka A, Zeitune JM, Andreollo NAGastric polyps: a retrospective analysis of 26,000 digestive endoscopies. Arq Gastroenterol 2007:44:14-7.

8. Goddard AF, Badreldin R, Pritchard DM, et al. The management of gastric polyps. Gut 2010;59:1270-6.

9. Oberhuber G, Stolte M. Gastric polyps: an update of their pathology and biological significance. Virchows Arch 2000;437:581-90.

10. Jain R, Chetty R. Gastric hyperplastik polyps: a review. Dig Dis Sci 2009;54:1839-46.

11. Dirschmid K, Platz-Baudin C, Stolte M. Why is the hyperplastic polyp a marker for the precancerous condition of the gastric mucosa? Virchows Arch 2006;448:80-4.

12. Zea-Iriarte WL, Sekine I, Itsuno M, et al. Carcinoma in gastric hyperplastic polyps. A phenotypic study. Dig Dis Sci 1996;41:377-86.

13. Orlowska J, Jarosz D, Pachlewski J, Butruk E. Malignant transformation of benign epithelial gastric polyps. Am J Gastroenterol. 1995;90:2152-9.

14. Daibo M, Itabashi M, Hirota T. Malignant transformation of gastric hyperplastic polyps. Am J Gastroenterol 1987;82:1016-25.

15. Carmack SW, Genta RM, Schuler CM, Saboorian MH. The current spectrum of gastric polyps: a 1-year national study of over 120.000 patients. Am J Gastroenterol 2009;104:1524-32.

16 Owen DA. The stomach, In: Sternberg SS, Editor. Diagnostic Surgical Pathology, 3rd ed. Philadelphia. Lippincott Williams \& Wilkins 1999; $1311-47$.

17. Choudhry U, Boyce HW Jr, Coppola D. Proton pump inhibitor-associated gastric polyps: a retrospective analysis of their frequency, and endoscopic, histologic, and ultrastructural characteristics. Am J Clin Pathol 1998;110:615-21.

18. Jalving M, Koornstra JJ, Wesseling J, et al. Increased risk of fundic gland polyps during long-term proton pump inhibitor therapy. Aliment Pharmacol Ther 2006;24:1341-8.

19. Stolte M, Sticht T, Eidt S, et al. Frequency, location, and age and sex distribution of various types of gastric polyp. Endoscopy 1994;26:659-65.

20. Kamiya T, Morishita T, Asakura H, et al. Long-term follow-up study on gastric adenoma and its relation to gastric protruded carcinoma. Cancer 1982;50:2496-503.

21. Nakamura T, Nakano G. Histopathological classification and malignant change in gastric polyps. J Clin Pathol 1985;38:754-64.

22. Pantanowitz L, Antonioli DA, Pinkus GS, et al. Inflammatory fibroid polyps of the gastrointestinal tract: evidence for a dendritic cell origin. Am J Surg Pathol 2004;28:107-14. 